Multidisciplinary

SCIENTIFIC JOURNAL OF MARITIME RESEARCH

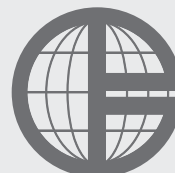

University of Rijeka

Faculty of Maritime

Studies Rijeka
Multidisciplinarni

znanstveni časopis

POMORSTVO

https://doi.org/10.31217/p.32.2.12

\title{
Energy and Exergy Analysis of the Condensate Pump During Internal Leakage from the Marine Steam Propulsion System
}

\author{
Igor Poljak ${ }^{1}$, Josip Orović ${ }^{1}$, Vedran Mrzljak ${ }^{2}$ \\ ${ }^{1}$ University of Zadar, Maritime Department, M. Pavlinovića 1, 23000 Zadar, Croatia, e-mail: ipoljak1@unizd.hr; jorovic@unizd.hr \\ ${ }^{2}$ Faculty of Engineering, University of Rijeka, Vukovarska 58, 51000 Rijeka, Croatia, e-mail: vmrzljak@riteh.hr
}

\section{ABSTRACT}

An energy and exergy analysis of the condensate pump from the marine steam propulsion system during the condensate leakage between pump stages is presented in this paper. Measurements from the steam propulsion system during exploitation were necessary for collecting all the data for the condensate pump analysis. Due to condensate leakage inside the pump casing, the producer specified condensate pressures at the pump outlet could not be obtained during the exploitation. Low condensate pressure at the pump inlet and condensate temperature slightly above the atmospheric significantly influences the pump exergy analysis. Increase in pump load resulted in an increase of pump energy and exergy losses and efficiencies. In the observed load range during the leakage, pump energy losses are between $19.88 \mathrm{~kW}$ and $24.78 \mathrm{~kW}$, while pump energy efficiencies are between 11.12 $\%$ and $41.54 \%$. Pump exergy losses are slightly higher, while exergy efficiencies are slightly lower when compared to energy losses and efficiencies. During normal operation, without leakage, the pump energy efficiencies are from $5 \%$ to $20 \%$ higher in comparison with pump operation when the leakage occurs.
\end{abstract}

\section{ARTICLE INFO}

Original Scientific Paper

Received 4 November

Accepted 19 November 2018

Key words:

Condensate pump

Internal leakage

Energy analysis

Exergy analysis

Steam propulsion system

\section{Introduction}

Diesel engines have a dominant role in marine propulsion if the entire world fleet is taken into account. Nowadays, a typical ship main engine room consists of one two-stroke slow speed diesel engine for the propulsion [1] and [2], while several four-stroke middle speed or fast speed diesel engines are used for electricity production [3]. The correct configuration of the propulsion system installed in the main engine room of each individual ship depends on a number of factors. In order to reduce harmful emissions from marine diesel engines (especially from two-stroke diesel engines which consume a significant amount of heavy fuel oil), new engine operation techniques have been developed, [4] and [5], with simultaneous usage of additives in heavy fuel oil [6].

Marine steam propulsion systems are only slightly present in the entire world fleet, but still they are dominant propulsion systems of LNG (Liquefied Natural Gas) carriers [7] due to specificity of LNG carrier operation and transported cargo. New systems for LNG carrier propulsion, partially based on steam turbines, are today under the development [8]. Such propulsion systems are very complex, so they require proper power management systems [9], decision support systems (usually multi-objective) [10] as well as appropriate maintenance systems [11]. Improvements on LNG carriers do not include only the propulsion system, but they also include optimal manipulation and management of the transported cargo [12].

The general scheme of a marine steam propulsion system is presented in Fig. 1[13]. Such propulsion system usually consists of two mirror-oriented boilers to ensure continuous superheated steam production. Each marine steam boiler has an air heater before air entrance into the boiler furnace [14]. Air heating in marine steam boilers is ensured with a small part of the produced superheated steam, because the flue gases from marine steam boilers do not have sufficient temperature for such heating purposes, unlike air heaters from conventional land-based steam power plants, [15] and [16]. 


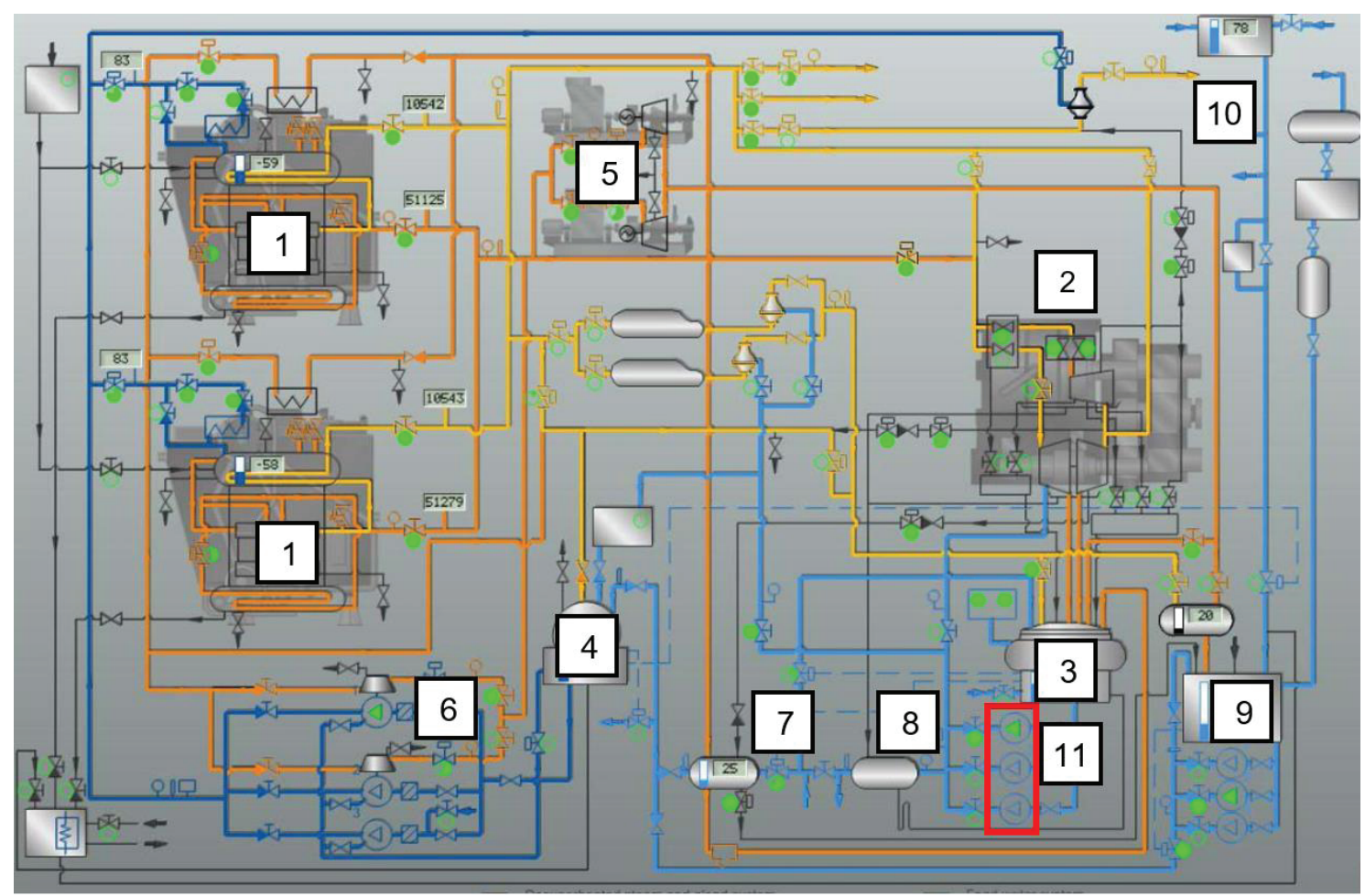

Fig. 1 General scheme of marine steam propulsion system [13]

1 - Main boilers, 2 - Propulsion turbine, 3 - Main condenser, 4 - Deaerator, 5 - Turbogenerators, 6 - Feed pumps, 7 - Low-pressure feed water heater, 8 - Gland steam condenser, 9 - Atmospheric drain tank, 10 - High-pressure bleed, 11 - Main condensate pumps

After the steam expansion in the main steam turbine, steam is led to the main condenser. The main condenser operation greatly differs if compared with steam condensers from conventional land-based power plants [17]. At a certain ship speed, cooling sea water is delivered to the main condenser by the scoop system (sea accumulation system) and pumps are not used in such main condenser operation regime. After steam condenses in the main condenser, generated condensate is taken by the condensate pump and delivered to the deaerator through the lowpressure condensate heating system.

Low-pressure condensate heating system consists of sealing steam condenser which collects steam omitted at outer labyrinth seals of all turbines installed in the marine propulsion system and uses that steam for condensate heating [18]. Additional condensate heating in the lowpressure heating system is ensured with one or more condensate heaters [19].

Deaerator divides condensate/feed water heating system in the low-pressure and high-pressure part. The deaerator has two main functions: the first is condensate heating [20] and the second is dissolved gases removal from the condensate with the aim of pipeline corrosion reduction. Between the deaerator and steam boilers one or more high-pressure feed water heaters can be found, which ensure additional feed water heating before its entrance into the steam boilers [21]. The feed water pressure increase and delivery from the deaerator to the boilers is ensured with the main feed water pumps.
In the marine steam propulsion system, a number of pressure reduction valves can be found [22] which are used for operating medium pressure reduction as well as regulation and control valves.

Auxiliary steam turbines are two parallel operating turbo-generators which ensure the continuous electricity production [23]. Another auxiliary steam turbine in the marine steam propulsion system is usually a low power steam turbine for the main feed water pump drive. Such low power steam turbines do not reach their maximum efficiencies at the highest load (unlike high power steam turbines) - the highest efficiencies of such low power steam turbines are reached at $70 \%-80 \%$ of maximum load, [24] and [25].

\section{Analyzed Condensate Pump Characteristics and Producer Test Data for Overall Efficiency}

As presented in Fig. 1, the condensate pump takes the condensate from the main condenser and increases its pressure. The condensate with the increased pressure is then delivered to the low-pressure condensate heating system. The condensate pump can be considered as heavyduty pump because the condensate from the main condenser has a very low pressure (usually 92 - $97 \%$ under the atmospheric pressure). Therefore, the high efficiency of such a pump cannot be expected. The steam propulsion system at any ship has usually two identical parallel connected condensate pumps. One pump is in operation while 
the other one is a spare pump on stand-by mode. If any significant problem or damage during normal operation of the condensate pump occurs, the condensate flow can be easily switched to another pump while the damaged pump can be repaired by the crew (or replaced by another new pump). The propulsion system of the analyzed LNG carrier has also another identical spare condensate pump.

The scheme and required operating points for the condensate pump energy and exergy analysis are presented in Fig. 2. The operating point 1 represents a low-pressure condensate stream from the main condenser while the operating point 2 represents a condensate stream at the pump outlet with significantly increased pressure. Unavoidable parameter for the condensate pump energy and exergy analysis is also the pump driving power $\left(P_{\mathrm{p}}\right)$ which is delivered to the condensate pump from the electric motor (EM). The electric motor is directly connected to the pump driving shaft, so the mechanical losses during power transmission can be neglected.

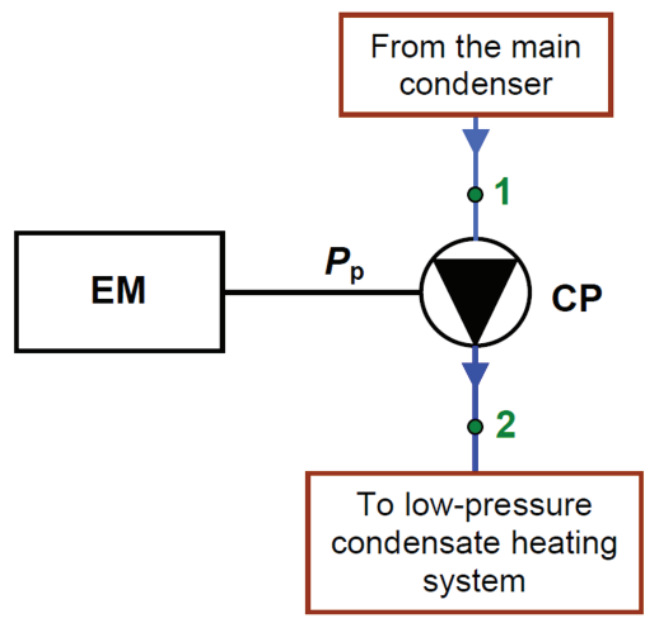

Fig. 2 Scheme and required operating points for condensate pump energy and exergy analysis (EM = Electric Motor; $\mathrm{CP}$ = Condensate Pump)

Main particulars of the analyzed centrifugal condensate pump along with general specifications of the electric motor for pump drive are presented in Table 1. The condensate pump operates in a steam propulsion system on board a conventional LNG carrier. On board that LNG carrier, during ship exploitation, measurements of required operating parameters for the condensate pump proper energy and exergy analysis have been performed.

The producer of the analyzed centrifugal condensate pump in [27] has presented a diagram of the change in the pump overall efficiency in regard to the condensate volume flow at the pump inlet. The diagram has been digitized and the change in the pump overall efficiency is presented in Table 2 for different condensate volume flows. Table 2 shows that the pump overall efficiency increases up to the condensate volume flow of $130.4 \mathrm{~m}^{3} / \mathrm{h}$ (volume flow over the design point - Table 1), after which the pump overall efficiency decreases.
Table 1 Particulars of the analyzed centrifugal condensate pump and driving electric motor [26]

\begin{tabular}{|l|c|}
\hline \multicolumn{2}{|c|}{ Design data } \\
\hline Pump model & EVZ130M \\
\hline Pump type & Centrifugal \\
\hline No. of stages & 2 \\
\hline Volume flow & $110 \mathrm{~m}^{3} / \mathrm{h}$ \\
\hline Total head & $95 \mathrm{~m}$ \\
\hline Suction head & Vacuum \\
\hline Pumping liquid & Condensate \\
\hline Liquid temperature & $33^{\circ} \mathrm{C}$ \\
\hline Hydraulic test & $1.9 \mathrm{MPa}$ \\
\hline Pump weight & $590 \mathrm{~kg}$ \\
\hline Pump casing thickness & $10 \mathrm{~mm}^{\mid 2}$ \\
\hline Water filled in pump casing & $48 \mathrm{~kg}$ \\
\hline Electric motor synchronous speed & $1800 \mathrm{~min}^{-1}$ \\
\hline Electric motor max. power & $55 \mathrm{~kW}$ \\
\hline
\end{tabular}

Table 2 Producer overall efficiency of the analyzed centrifugal condensate pump [27]

\begin{tabular}{|c|c|}
\hline $\begin{array}{c}\text { Condensate volume flow } \\
\left(\mathbf{m}^{\mathbf{3}} \mathbf{/} \mathbf{h}\right.\end{array}$ & $\begin{array}{c}\text { Overall efficiency } \\
\mathbf{( \% )}\end{array}$ \\
\hline 5.0 & 7.0 \\
\hline 10.0 & 14.0 \\
\hline 15.0 & 20.0 \\
\hline 20.0 & 25.0 \\
\hline 25.0 & 30.0 \\
\hline 30.0 & 35.0 \\
\hline 35.0 & 39.0 \\
\hline 40.0 & 43.0 \\
\hline 45.0 & 46.0 \\
\hline 50.0 & 48.0 \\
\hline 55.0 & 51.0 \\
\hline 65.0 & 56.0 \\
\hline 70.0 & 58.0 \\
\hline 75.0 & 59.0 \\
\hline 80.0 & 60.0 \\
\hline 90.0 & 62.0 \\
\hline 130.4 & 64.7 \\
\hline 137.1 & 63.6 \\
\hline & \\
\hline
\end{tabular}

The same values from Table 2 are approximated with $6^{\text {th }}$ degree polynomial for a faster calculation of the analyzed pump overall efficiency according to the producer specifications:

$\eta_{\mathrm{PPE}}(\dot{V})=-3.982 \cdot 10^{-11} \cdot \dot{V}^{6}+1.522119 \cdot 10^{-8} \cdot \dot{V}^{5}-$

$-2.19704579 \cdot 10^{-6} \cdot \dot{V}^{4}+1.7969357 \cdot 10^{-4} \cdot \dot{V}^{3}-$

$-1.6328063 \cdot 10^{-2} \cdot \dot{V}^{2}+1.5394097 \cdot \dot{V}-$ 
In equation (1), the condensate volume flow at the pump inlet $\dot{V}$ must be inserted in $\left(\mathrm{m}^{3} / \mathrm{h}\right)$ to obtain efficiency $\eta_{P P E}$ in (\%). Equation (1) will be used for the comparison of the condensate pump energy efficiencies at various loads obtained by this analysis with overall efficiencies specified by the producer.

\section{Energy and Exergy Analysis}

\subsection{Energy and Exergy Analysis of Any Control Volume}

For any control volume (or the entire observed system), the same overall equations for the energy and exergy analysis can be set up. The first law of thermodynamics defines energy analysis [28]. Energy analysis of any system or control volume is related to the conservation of energy [29]. Mass and energy balance equations for a control volume in steady state can be expressed according to [30] and [31] by equations:

$$
\begin{aligned}
& \sum \dot{m}_{\mathrm{IN}}=\sum \dot{m}_{\text {OUT }} \\
& \dot{Q}_{\mathrm{IN}}+P_{\mathrm{IN}}+\sum \dot{m}_{\mathrm{IN}} \cdot\left(h+\frac{c^{2}}{2}+g \cdot z\right)_{\mathrm{IN}}=\dot{Q}_{\mathrm{OUT}}+ \\
& +P_{\mathrm{OUT}}+\sum \dot{m}_{\mathrm{OUT}} \cdot\left(h+\frac{c^{2}}{2}+g \cdot z\right)_{\text {OUT }}
\end{aligned}
$$

The cumulative energy flow for any fluid stream should be calculated according to [14] as:

$$
\dot{E}_{\text {en }}=\dot{m} \cdot h
$$

A general equation for energy efficiency of any system or control volume is [32]:

$$
\eta_{\mathrm{en}}=\frac{\text { Energy output }}{\text { Energy input }}
$$

From the second law of thermodynamics, the definition of exergy analysis can be derived [33]. The main exergy balance equation according to [24] and [34] can be defined as:

$$
\Sigma(\dot{m} \cdot \varepsilon)_{\mathrm{IN}}+\dot{X}_{\text {heat }}=\sum(\dot{m} \cdot \varepsilon)_{\mathrm{OUT}}+P+\dot{E}_{\mathrm{ex}, \mathrm{L}}
$$

The exergy transfer by heat $\left(\dot{X}_{\text {heat }}\right)$ at the temperature $T$ is defined as [35]:

$$
\dot{X}_{\text {heat }}=\sum\left(1-\frac{T_{0}}{T}\right) \cdot \dot{Q}
$$

According to [36] and [37], specific exergy of any fluid stream can be defined by the following equation:

$$
\varepsilon=\left(h-h_{0}\right)-T_{0} \cdot\left(s-s_{0}\right)
$$

The cumulative exergy flow for any fluid stream can be expressed according to [38] and [39] with the following equation:

$$
\dot{E}_{\mathrm{ex}}=\dot{m} \cdot \varepsilon=\dot{m} \cdot\left[\left(h-h_{0}\right)-T_{0} \cdot\left(s-s_{0}\right)\right]
$$

Exergy efficiency in the most cases (for any system or control volume) can be defined as [40]:

$$
\eta_{\text {ex }}=\frac{\text { Exergy output }}{\text { Exergy input }}
$$

These governing equations, from equation (2) to equation (10), have been used in the condensate pump energy and exergy analysis.

\subsection{Condensate Pump Energy and Exergy Analysis}

Equations for the condensate pump energy and exergy analysis will be presented in accordance with the pump operating points from Fig. 2 . The required specific enthalpies, specific entropies and specific exergies as well as other condensate thermodynamic properties have been calculated from the measured condensate pressures and temperatures at the pump inlet and outlet for each load by using the NIST REFPROP 9.0 software [41].

Pump exergy analysis depends on the conditions of the ambient in which the pump (or any other control volume) operates. Measurements during LNG carrier exploitation have been performed during the following ambient conditions:

- Ambient pressure: $\quad p_{0}=0.1 \mathrm{MPa}=1 \mathrm{bar}$,

- Ambient temperature: $T_{0}=25{ }^{\circ} \mathrm{C}=298.15 \mathrm{~K}$.

For the analyzed condensate pump - mass, energy and exergy balances are (according to Fig. 2):

Mass balance:

$$
\dot{m}_{1}=\dot{m}_{2}
$$

Energy balance:

- Energy power input (from condensate flow only):

$$
\dot{E}_{\mathrm{en}, \mathrm{IN}, \mathrm{con}}=\dot{m}_{1} \cdot h_{1}
$$

- Energy power input (cumulative energy power input):

$$
\dot{E}_{\text {en,IN,cum }}=\dot{m}_{1} \cdot h_{1}+P_{\mathrm{p}}
$$

- Energy power output:

$$
\dot{E}_{\text {en,OUT }}=\dot{m}_{2} \cdot h_{2}
$$

- Energy loss (energy power loss):

$$
\dot{E}_{\mathrm{en}, \mathrm{L}}=\dot{E}_{\mathrm{en}, \mathrm{IN}, \mathrm{cum}}-\dot{E}_{\mathrm{en}, \mathrm{OUT}}=\dot{m}_{1} \cdot h_{1}+P_{\mathrm{p}}-\dot{m}_{2} \cdot h_{2}
$$

- Energy efficiency [42]:

$$
\eta_{\mathrm{en}}=\frac{\dot{E}_{\mathrm{en}, \mathrm{OUT}}-\dot{E}_{\mathrm{en}, \mathrm{IN}, \mathrm{con}}}{P_{\mathrm{p}}}=\frac{\dot{m}_{2} \cdot h_{2}-\dot{m}_{1} \cdot h_{1}}{P_{\mathrm{p}}}
$$

Exergy balance:

- Exergy power input (from condensate flow only):

$$
\dot{E}_{\text {ex,IN,con }}=\dot{m}_{1} \cdot \varepsilon_{1}
$$

- Exergy power input (cumulative exergy power input):

$$
\dot{E}_{\mathrm{ex}, \mathrm{IN}, \mathrm{cum}}=\dot{m}_{1} \cdot \varepsilon_{1}+P_{\mathrm{p}}
$$


- Exergy power output:

$$
\dot{E}_{\text {ex,OUT }}=\dot{m}_{2} \cdot \varepsilon_{2}
$$

- Exergy loss (exergy power loss):

$$
\dot{E}_{\mathrm{ex}, \mathrm{L}}=\dot{E}_{\mathrm{ex}, \mathrm{IN}, \mathrm{cum}}-\dot{E}_{\mathrm{ex}, \mathrm{OUT}}=\dot{m}_{1} \cdot \varepsilon_{1}+P_{\mathrm{p}}-\dot{m}_{2} \cdot \varepsilon_{2}
$$

- Exergy efficiency [43]:

$$
\eta_{\mathrm{ex}}=\frac{\dot{E}_{\mathrm{ex}, \mathrm{OUT}}-\dot{E}_{\mathrm{ex}, \mathrm{IN}, \mathrm{con}}}{P_{\mathrm{p}}}=\frac{\dot{m}_{2} \cdot \varepsilon_{2}-\dot{m}_{1} \cdot \varepsilon_{1}}{P_{\mathrm{p}}}
$$

\section{Measurement Results and Measuring Equipment}

Measurements of the required operating parameters have been performed during the steam propulsion system exploitation. Measured and calculated values for the condensate at the analyzed pump inlet and outlet are presented in Table 3. Measured values at the pump inlet are condensate temperature, pressure and mass flow. By using the measured data for the condensate at the pump inlet, the condensate density has been calculated with NIST REFPROP 9.0 software [41] and from the condensate density the volume flow has been calculated. The reason for the condensate inlet volume flow calculation has been its usage in equation (1), in order to compare the results of the pump energy efficiency change obtained by this analysis with the producer test data.

The condensate temperature and condensate pressure have been measured at the pump outlet. Any pump, as well as the condensate pump, increases liquid temperature, but for a small value. On the other side, an increase in liquid (in this analysis condensate) pressure is considerable. The condensate pressure at the pump outlet in all pump

\begin{tabular}{|c|c|c|c|c|c|c|c|c|}
\hline \multirow[b]{2}{*}{ P.S.L.* } & \multirow{2}{*}{$\begin{array}{l}\text { Pump load } \\
\text { (\%) }\end{array}$} & \multicolumn{5}{|c|}{ CONDENSATE INLET $\left(1^{* *}\right)$} & \multicolumn{2}{|c|}{ CONDENSATE OUTLET $\left(2^{* *}\right)$} \\
\hline & & $\begin{array}{c}\text { Temperature } \\
\left({ }^{\circ} \mathrm{C}\right)\end{array}$ & $\begin{array}{l}\text { Pressure } \\
\text { (MPa) }\end{array}$ & $\begin{array}{c}\text { Mass flow } \\
(\mathrm{kg} / \mathrm{h})\end{array}$ & $\begin{array}{l}\text { Density } \\
\left(\mathrm{kg} / \mathrm{m}^{3}\right)\end{array}$ & $\begin{array}{c}\text { Volume flow } \\
\left(\mathrm{m}^{3} / \mathbf{h}\right)\end{array}$ & $\begin{array}{c}\text { Temperature } \\
\left({ }^{\circ} \mathrm{C}\right)\end{array}$ & $\begin{array}{l}\text { Pressure } \\
\text { (MPa) }\end{array}$ \\
\hline 1 & 10.93 & 36.81 & 0.006224 & 11943 & 993.36 & 12.02 & 36.83 & \multirow{25}{*}{$0.75^{* * *}$} \\
\hline 2 & 26.42 & 34.26 & 0.005408 & 28899 & 994.24 & 29.07 & 34.28 & \\
\hline 3 & 29.40 & 33.27 & 0.005118 & 32168 & 994.57 & 32.34 & 33.29 & \\
\hline 4 & 26.88 & 32.48 & 0.004895 & 29412 & 994.83 & 29.56 & 32.50 & \\
\hline 5 & 40.39 & 33.23 & 0.005105 & 44191 & 994.59 & 44.43 & 33.25 & \\
\hline 6 & 33.42 & 30.00 & 0.004250 & 36604 & 995.61 & 36.77 & 30.01 & \\
\hline 7 & 41.86 & 30.10 & 0.004276 & 45847 & 995.57 & 46.05 & 30.12 & \\
\hline 8 & 41.45 & 30.26 & 0.004316 & 45391 & 995.53 & 45.59 & 30.28 & \\
\hline 9 & 44.25 & 31.05 & 0.004513 & 48451 & 995.29 & 48.68 & 31.06 & \\
\hline 10 & 46.34 & 28.60 & 0.003921 & 50771 & 996.02 & 50.97 & 28.62 & \\
\hline 11 & 47.81 & 28.77 & 0.003961 & 52384 & 995.97 & 52.60 & 28.79 & \\
\hline 12 & 50.63 & 29.11 & 0.004039 & 55459 & 995.87 & 55.69 & 29.13 & \\
\hline 13 & 49.82 & 29.11 & 0.004039 & 54571 & 995.87 & 54.80 & 29.13 & \\
\hline 14 & 51.10 & 28.83 & 0.003974 & 55985 & 995.95 & 56.21 & 28.85 & \\
\hline 15 & 52.52 & 28.83 & 0.003974 & 57536 & 995.95 & 57.77 & 28.85 & \\
\hline 16 & 53.09 & 28.89 & 0.003987 & 58158 & 995.94 & 58.40 & 28.90 & \\
\hline 17 & 57.87 & 29.28 & 0.004079 & 63386 & 995.82 & 63.65 & 29.30 & \\
\hline 18 & 59.71 & 29.45 & 0.004118 & 65403 & 995.77 & 65.68 & 29.47 & \\
\hline 19 & 64.10 & 29.78 & 0.004197 & 70204 & 995.67 & 70.51 & 29.80 & \\
\hline 20 & 69.62 & 29.89 & 0.004224 & 76248 & 995.64 & 76.58 & 29.90 & \\
\hline 21 & 68.65 & 30.32 & 0.004329 & 75179 & 995.51 & 75.52 & 30.33 & \\
\hline 22 & 72.70 & 34.69 & 0.005539 & 79498 & 994.10 & 79.97 & 34.71 & \\
\hline 23 & 73.26 & 34.56 & 0.005500 & 80114 & 994.14 & 80.59 & 34.58 & \\
\hline 24 & 76.11 & 34.78 & 0.005566 & 83221 & 994.07 & 83.72 & 34.80 & \\
\hline 25 & 77.30 & 34.91 & 0.005605 & 84524 & 994.02 & 85.03 & 34.92 & \\
\hline
\end{tabular}
operating regimes, presented in Table 3 , has been around

Table 3 Measured and calculated values for condensate at analyzed pump inlet and outlet

* P.S.L. = Propulsion System Load (1 = the lowest load; 25 = the highest load)

** Condensate streams numeration refers to Fig. 2.

*** Pressure at the pump outlet is not always constant (differences have been at the third or fourth decimal place). Such differences cause negligible changes in the condensate specific enthalpy or specific exergy at the pump outlet for each operating point, therefore only the basic value is specified. 
Table 4 Measuring equipment used for the condensate pump analysis

\begin{tabular}{|c|c|l|}
\hline Position & Measured parameter & \multicolumn{1}{c|}{ Measurement equipment } \\
\hline \multirow{3}{*}{ Pump Inlet } & Temperature & Greisinger GTF 401-Pt100 - Immersion probe [44] \\
\cline { 2 - 3 } & Pressure & Yamatake JTG940A - Pressure transmitter [45] \\
\cline { 2 - 3 } & Mass flow & Promass 80F - Coriolis mass flow measuring system [46] \\
\hline \multirow{2}{*}{ Pump Outlet } & Temperature & Greisinger GTF 401-Pt100 - Immersion probe [44] \\
\cline { 2 - 3 } & Pressure & Yamatake JTG960A - Pressure transmitter [45] \\
\hline
\end{tabular}

$0.75 \mathrm{MPa}$ (7.5 bar). Small changes in the condensate outlet pressure, which are not presented in Table 3 , have caused a negligible change in the condensate specific enthalpies and specific exergies at the pump outlet necessary for the energy and exergy analysis. During the measurements, there has been no condensate leakage outside the pump casing, so the outlet condensate mass flow remains the same as the inlet one, for any operating point.

Table 3 is designed according to the propulsion system load - from the lowest to the highest propulsion system load. The condensate pump load is calculated as a ratio of the current and design condensate volume flow (design condensate volume flow is $110 \mathrm{~m}^{3} / \mathrm{h}$ - Table 1). As it can be seen, pump load generally increases during the increase in the steam system load, but that increase is not directly proportional. For example, an increase in the propulsion system load from point 5 to point 6 has resulted in a decrease in the condensate pump load from $40.39 \%$ to $33.42 \%$, Table 3. Regardless of this fact, figures from Fig. 3 to Fig. 10 are prepared and presented by using data for the condensate pump load from Table 3.

All the measured results have been obtained by using the measuring equipment installed in the main engine room on board the conventional LNG carrier with steam propulsion. This equipment is used by a ship engine crew for regulation and proper management of the entire propulsion system. The measurement equipment used in the analysis is listed in Table 4.

The last operating parameter required for the proper condensate pump energy and exergy analysis is the pump driving power, which is delivered to the pump by an electric motor. The most important specifications of the electric motor for the analyzed pump drive are presented in Table 1. The electric motor current is measured for each observed condensate pump load by using the standard ship current measuring equipment [47]. The electric motor power factor $(\cos \varphi)$ is equal to 0.941 , while the electric motor voltage is $440 \mathrm{~V}$ [27]. By knowing these data, according to [48] and [49], the power delivered from the electric motor to the condensate pump (pump driving power $-P_{\mathrm{p}}$ ) can be calculated by using the following equation:

$$
P_{\mathrm{p}}=\sqrt{3} \cdot I \cdot U \cdot \cos \varphi
$$

where current $I$ should be placed in (A) and voltage $U$ should be placed in (V) to obtain the condensate pump driving power $P_{\mathrm{p}}$ in $(\mathrm{W})$.
The electric motor measured current and calculated condensate pump driving power in relation to the pump load are presented in Fig. 3. It can be generally concluded, from Fig. 3, that the increase in the condensate pump load causes a continuous increase in the electric motor current and produced driving power (along with some smaller deviations from this conclusion, which are usual for real driving conditions during exploitation).

\section{Results of the Energy and Exergy Analysis for the Condensate Pump with Discussion}

The condensate pump cumulative energy power input must be higher at each pump load when compared to the energy power output, Fig. 4. Trend lines presented in Fig. 4 show that both cumulative pump energy power input and output continuously increase during the increase in the pump load.

At the lowest observed pump load of $10.93 \%$, the cumulative energy power input is $533.89 \mathrm{~kW}$, while at the same load energy power output it is equal to $514.01 \mathrm{~kW}$. At the highest observed pump load, the cumulative energy power input is equal to $3475.94 \mathrm{~kW}$, while the pump energy power output is $3451.16 \mathrm{~kW}$, Fig. 4.

The highest observed condensate pump load during measurements has been $77.30 \%$ (the condensate volume flow at pump inlet has been $77.30 \%$ of the design volume flow - Table 1). During the LNG carrier exploitation (when the measurements have been performed), a greater volume flow through the condensate pump has not been required and, therefore, the pump could not be tested at the design or maximum volume flow.

As presented in equation (13), the cumulative condensate pump energy power input consists of the condensate energy power input (energy amount which the condensate from the main condenser brings into the pump) and of the driving power delivered to the pump by an electric motor. It is interesting to investigate and present shares of these two cumulative energy power input components for each observed pump load, Fig. 5.

Fig. 5 clearly shows that, for the analyzed condensate pump, the majority of the cumulative energy power input refers to the condensate energy power input, while only a small amount of the cumulative energy power input is brought to the pump by an electric motor through the delivered power. This conclusion is valid for each observed condensate pump load. The increase in the condensate 


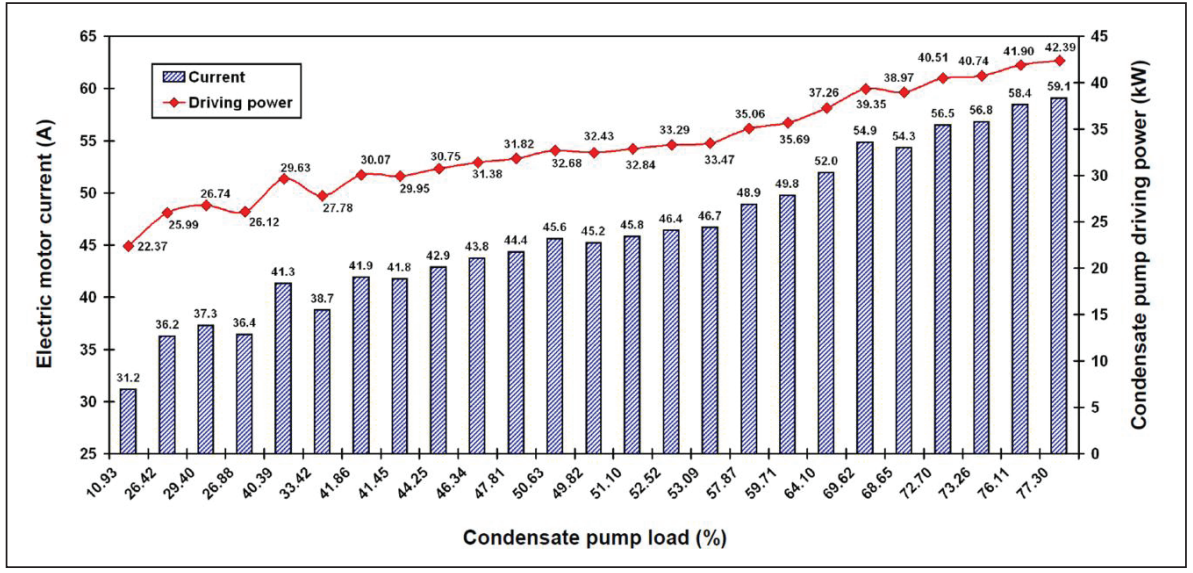

Fig. 3 Change in the measured electric motor current and calculated condensate pump driving power during the increase in the pump load

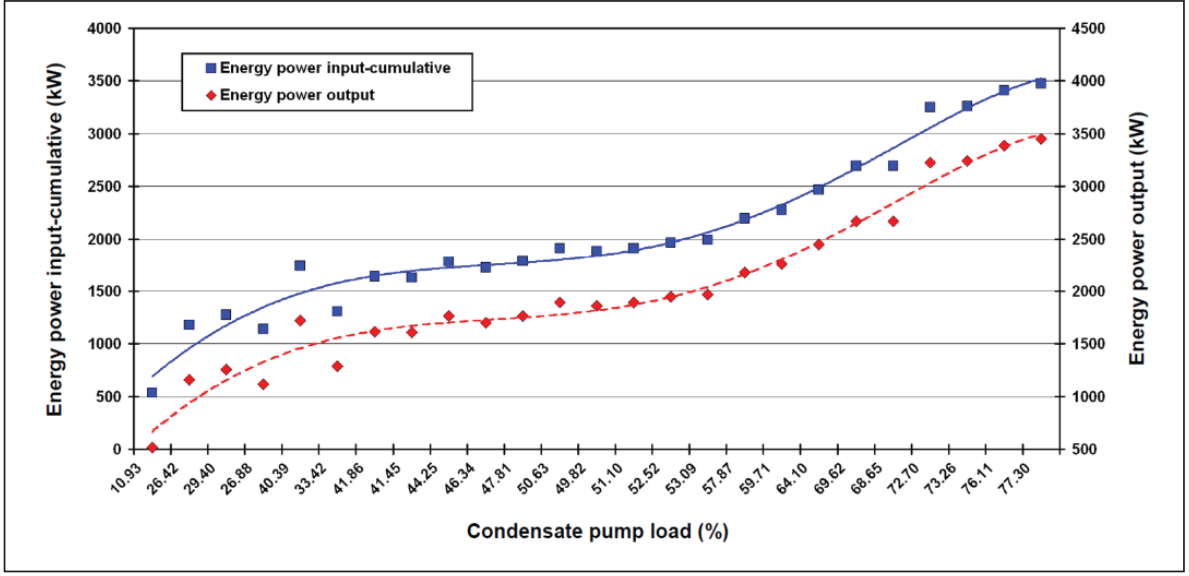

Fig. 4 Change in the condensate pump cumulative energy power input and energy power output during the increase in the pump load

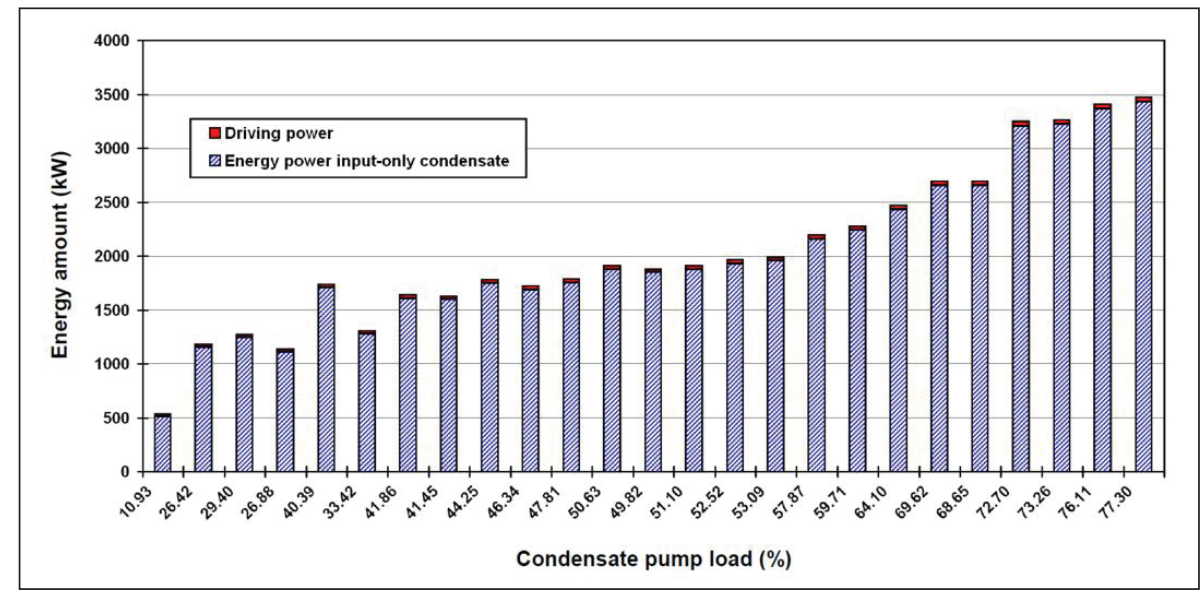

Fig. 5 Change in the shares of the condensate energy power input and driving power in the pump cumulative energy power input during the increase in the pump load

pump load has resulted with the fact that the share of the driving power in the cumulative pump energy power input decreases (from $4.19 \%$ at the lowest to the $1.22 \%$ at the highest observed pump load). Therefore, it can be concluded that the cumulative pump energy power input is not equally distributed on its constituent components the condensate energy amount is the dominant one. It will be also interesting to carry out research on this distribution of the condensate pump cumulative exergy power input, at each observed pump load, and compare it with the obtained conclusions for the energy input.

Similar to the cumulative energy power input and output, the condensate pump cumulative exergy power input and output continuously increases during the increase in 
the pump load, Fig. 6. From the lowest to the highest observed pump load (from $10.93 \%$ to $77.30 \%$ ), the cumulative pump exergy power input increases from $25.22 \mathrm{~kW}$ to $55.96 \mathrm{~kW}$, while in the same pump load range the exergy power output increases from $5.33 \mathrm{~kW}$ to $31.15 \mathrm{~kW}$. As for the energy cumulative power input and output, the same conclusion is valid for the cumulative exergy power input and output of the analyzed pump - the pump cumulative exergy power input must be higher at each observed load in comparison with the pump exergy power output, Fig. 6.

The comparison of Fig. 4 and Fig. 6 leads to the conclusion that trends in cumulative energy and exergy power inputs and outputs, during the increase in the pump load, are the same. The notable difference is that cumulative exergy power inputs and outputs have a much lower value in comparison with the cumulative energy power inputs and outputs. Such small values of the condensate pump exergy inputs and outputs can be easily explained by the fact that condensate temperatures at the pump inlet and outlet, for each pump load, are very close to the ambient temperature (and simultaneously, the condensate pressure at the pump inlet is considerably below the atmospheric one Table 3).
Equation (18) presents that the cumulative exergy power input of the analyzed condensate pump consists of two parts (identical to the cumulative energy power input) - the first part is the condensate exergy power input (exergy brought to the pump by the condensate flow at the pump inlet) and the second part is the pump driving power delivered by an electric motor. Due to low pressures of the condensate at the pump inlet (condensate is delivered to the pump at main condenser pressure), the condensate exergy power input has extremely low values, Fig. 7. In some pump operating regimes, the condensate exergy power input is a bit above zero (pump loads between $46.34 \%$ and $57.87 \%$ ), while it reaches values over $10 \mathrm{~kW}$ only at the highest observed condensate pump loads, Fig. 7. The dominant part of the cumulative exergy power input at each load of the analyzed condensate pump is driving power delivered from the electric motor.

The comparison of Fig. 5 and Fig. 7 presents one of the main differences of the condensate pump energy and exergy analysis. As it can be seen from Fig. 5 - low pressure of condensate at the pump inlet has a very small impact on the energy content of the condensate, so the condensate energy is the dominant part of the pump cumulative en-

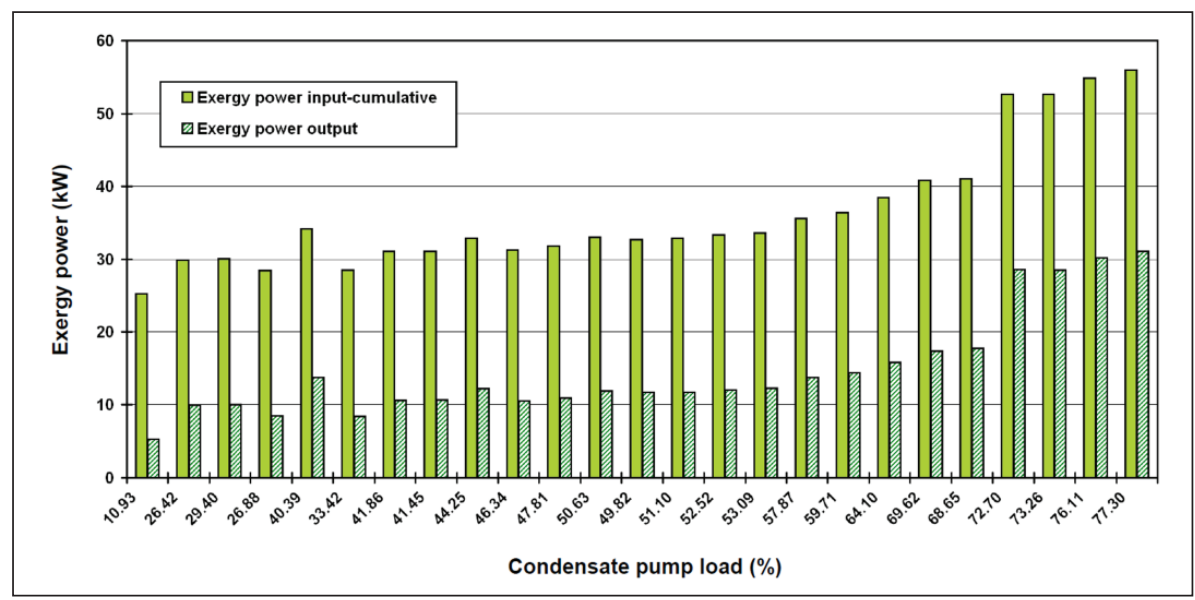

Fig. 6 Change in the condensate pump cumulative exergy power input and exergy power output during the increase in the pump load

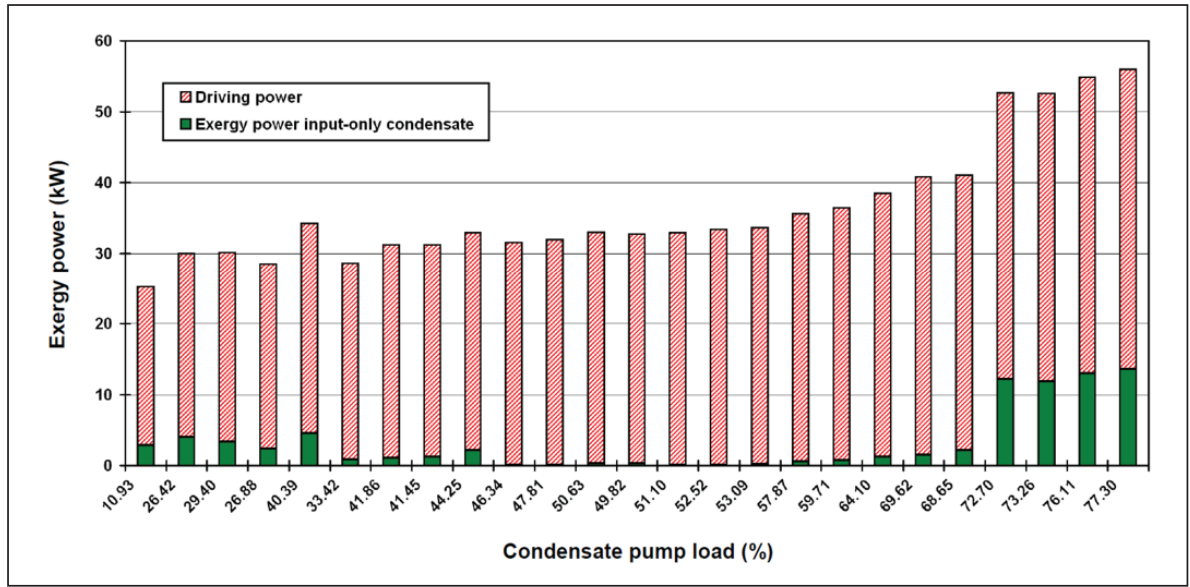

Fig. 7 Change in the shares of the condensate exergy power input and driving power in the pump cumulative exergy power input during the increase in the pump load 
ergy power input. Low pressure (and simultaneous temperature only slightly above the ambient temperature) of the condensate at the pump inlet significantly influences the condensate exergy content and its values are extremely low. So, in the cumulative exergy power input of the analyzed condensate pump, the power delivered to the pump by an electric motor has a dominant role.

The increase in the steam system (or any steam system component) load leads to the increase in energy and exergy power losses of the whole system and the most of the system components [50]. This conclusion is valid for any steam system or steam power plant, and not for marine steam propulsion systems only. The same trend can be seen for the analyzed condensate pump, Fig. 8, because the increase in the condensate pump load has resulted in the continuous increase in pump energy and exergy losses.

From the lowest to the highest observed condensate pump load, energy losses increase from $19.88 \mathrm{~kW}$ up to $24.78 \mathrm{~kW}$, while in the same pump load range exergy losses also increase from $19.89 \mathrm{~kW}$ up to $24.81 \mathrm{~kW}$. At each condensate pump load, energy losses are lower in comparison to exergy losses, but the differences between those two losses are small - even at the highest observed condensate pump loads.
The condensate pump energy and exergy efficiencies during the increase in the pump load have the same trend as the pump energy and exergy losses. In Fig. 9, it can be seen that the increase in the pump load has resulted in a continuous increase in the pump energy and exergy efficiencies. The sharpest increase in both efficiencies can be observed at lower pump loads - from the middle to the highest pump loads, the increase in both efficiencies is still consistent, but not as sharp as at lower loads.

In the observed pump load range, the energy efficiency increases from $11.12 \%$ (pump load of $10.93 \%$ ) up to $41.54 \%$ (the highest observed pump load of $77.30 \%$ ). The pump exergy efficiency in the same load range increases from $11.10 \%$ (load of $10.93 \%$ ) to $41.47 \%$ (load of $77.30 \%$ ). It can be concluded that, for each condensate pump load, the pump energy efficiency has a higher value when compared to the pump exergy efficiency due to slightly lower energy power losses at each observed pump load - Fig. 8.

As expected, the highest condensate pump efficiencies have been obtained at the highest pump load where the majority of pump (and entire steam system) operations can be expected.

Finally, the authors have compared the results of the change in the condensate pump energy efficiencies ob-

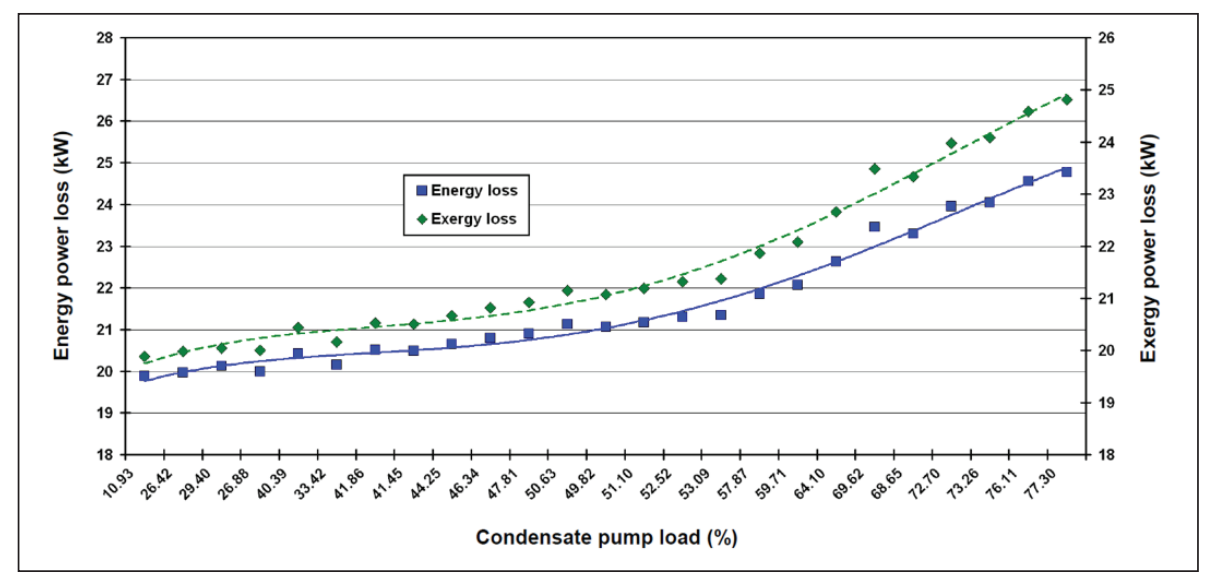

Fig. 8 Change in the condensate pump energy and exergy losses during the increase in the pump load

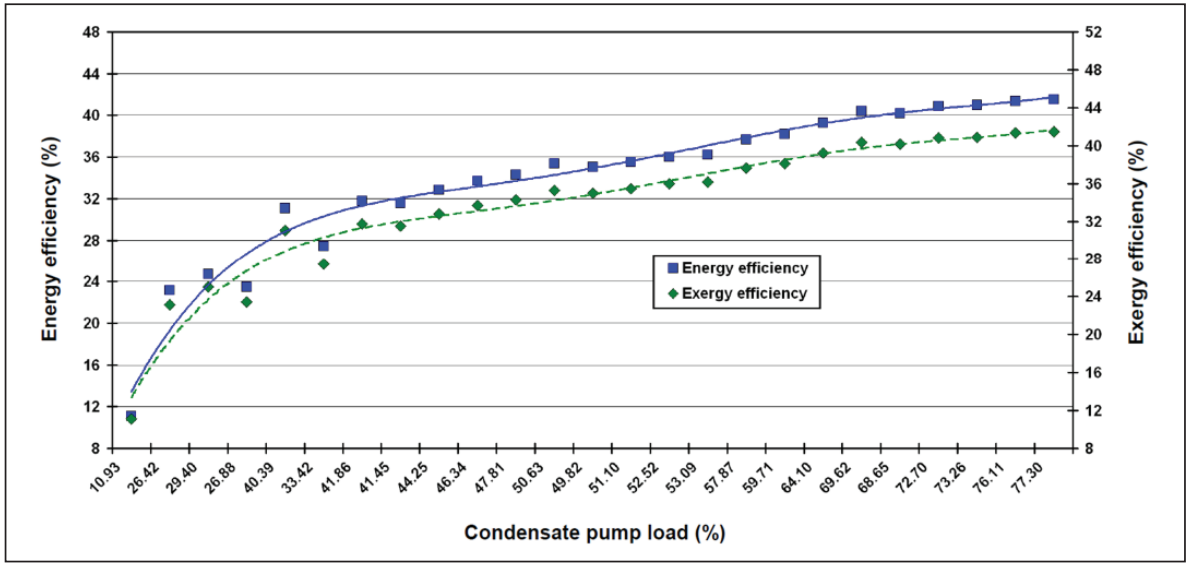

Fig. 9 Change in the condensate pump energy and exergy efficiencies during the increase in the pump load 


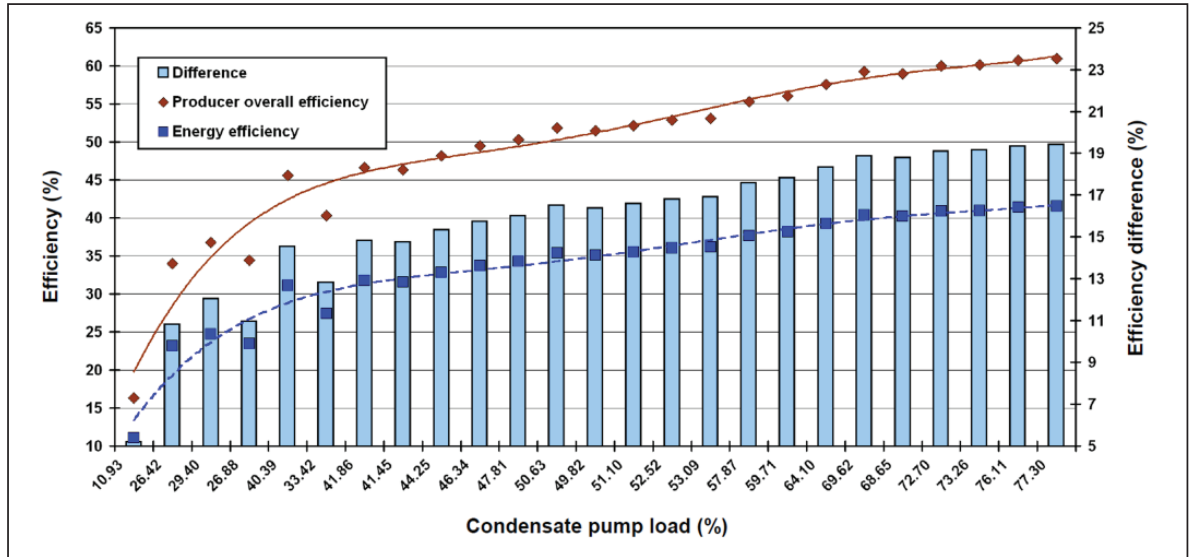

Fig. 10 Change and difference between the condensate pump producer overall efficiency and energy efficiency obtained by this analysis

tained by this analysis (according to real measured operating parameters) with the producer specified overall pump efficiency from Table 2. For a faster calculation of the producer overall efficiency, the developed $6^{\text {th }}$ degree polynomial has been used - equation (1). The expectation of the authors has been that those two efficiencies will differ in the range from 2 to $4 \%$, because efficiency of any steam system component during exploitation is usually lower when compared to the producer specifications [51]. A comparison of both efficiencies for each observed condensate pump load is presented in Fig. 10.

As it can be seen from Fig. 10, the similar shape of the condensate pump energy efficiency curve has been obtained during the increase in the pump load. The difference is that the analysis has shown much lower efficiencies than the producer has specified. The difference in the calculated pump energy efficiency and producer overall efficiency increases during the increase in the pump load - from $5.21 \%$ at the lowest to $19.44 \%$ at the highest observed pump load. Such energy efficiency differences are surely not the expectable ones, so all the calculations have been made again and the same results have been obtained.

A detailed insight into the analyzed pump producer specifications have shown that, in the observed operating range, for the observed condensate volume flows at the pump inlet - the condensate pressure at the pump outlet should be between 1.05 MPa and 1.1 MPa [27] (the measured condensate pressure at the pump outlet has been around $0.75 \mathrm{MPa}$ - Table 3). Since no leakage of the condensate has been detected outside the pump casing, the only remaining possibility has been to change over pumps and start the identical stand-by spare condensate pump. After the change over, the analyzed pump casing has been opened and examined for possible reasons of such an unexpected reduction in the condensate outlet pressure.

The reason for the condensate outlet pressure reduction has been found very fast - a hole in the pump casing has been found at the second stage inlet, Fig. 11. Through this hole, one part of the condensate has returned back to the intake of the first stage of the pump. An unexpected condensate circulation between the pump stages has re- sulted in a noticeable condensate outlet pressure drop, with no condensate leakage outside the pump casing to the main engine room.

At the end of this research, the authors have made the energy and exergy analysis of the condensate pump for the third time. It has been assumed that, in a usual operating regime, the pump will operate with the same operating parameters as presented in the paper, but outlet pressure has been set to 1.1 MPa. The third calculation of the pump energy efficiencies for all observed pump loads presented in this paper, has shown much higher energy efficiency values, especially at the highest observed loads. The comparison of the calculated pump energy efficiencies with the pump producer overall efficiencies at the end of the third calculation has resulted in the differences ranging from 1 to $3 \%$.

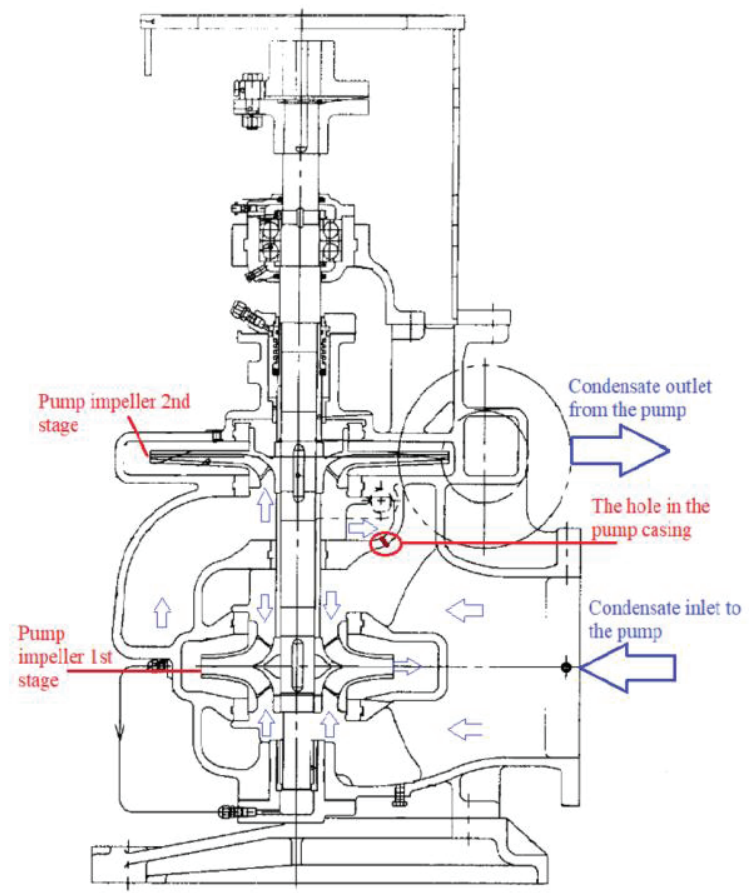

Fig. 11 Cross-section of the analyzed condensate pump with marked hole position in the pump casing at the inlet of the $2^{\text {nd }}$ stage impeller 


\section{Conclusions}

In this paper, the energy and exergy analysis of the condensate pump during the condensate leakage between pump stages has been presented. The analyzed condensate pump is one of the essential components of the steam propulsion system on board the conventional LNG carrier. Based on the pump measurement results obtained during exploitation at various loads, a complete energy and exergy analysis has been performed. Numerical analysis results have been compared with the pump producer test data and discrepancies have been obtained. This has been the reason to stop and examine the internal elements of the pump. The hole in the pump casing at the second stage inlet has been the reason of the condensate leakage inside the pump. During this failure, the pump has not been able to deliver the condensate at the producer specified pressures. The main conclusions from the provided analysis during the pump internal leakage are:

- Condensate pump cumulative energy and exergy power inputs and outputs continuously increases during the increase in the pump load,

- Cumulative energy power input into the pump is the most dependable on the condensate energy flow,

- Cumulative exergy power input into the pump is the most dependable on the pump driving power delivered by an electric motor,

- Low condensate pressure at the pump inlet and condensate temperature slightly above the atmospheric significantly influence the pump exergy analysis,

- Increase in the pump load has resulted in an increase of the pump energy and exergy losses and efficiencies,

- For the observed pump loads, the range of the pump energy losses during the pump leakage have been between $19.88 \mathrm{~kW}$ and $24.78 \mathrm{~kW}$, while the exergy losses have been slightly higher,

- The range of the pump energy efficiencies for the observed pump loads and during the pump leakage has been between $11.12 \%$ and $41.54 \%$, while the exergy efficiencies have been slightly lower,

- A pump outlet pressure increase in the mathematical model, with other operating parameters remaining the same as presented, has resulted in a pump efficiency change as to the producer specification,

- During the normal operation, without leakage, the pump energy efficiencies range from $16 \%$ up to $61 \%$ at the observed loads.

All the main conclusions obtained by this analysis during the condensate leakage between pump stages have been valid also during the pump normal operation, without any leakage. The difference has been only in the values of energy and exergy inputs and outputs, losses and efficiencies at each observed pump load.

Acknowledgments: The main ship-owner office team is highly acknowledged for conceding measuring equip- ment and for understanding our needs during the exploitation measurements. This work was supported by the University of Rijeka (contract No. 13.09.1.1.05) and the Croatian Science Foundation - Project DEcision Support SystEm for Green and Safe Ship RouTing.

\section{Nomenclature}

\begin{tabular}{|c|c|c|c|}
\hline \multicolumn{2}{|c|}{ Latin symbols: } & \multicolumn{2}{|c|}{ Greek symbols: } \\
\hline$c$ & velocity, m/s & $\varepsilon$ & specific exergy, kJ/kg \\
\hline$\dot{E}$ & $\begin{array}{l}\text { stream flow power, } \\
\text { kW }\end{array}$ & $\rho$ & density, $\mathrm{kg} / \mathrm{m}^{3}$ \\
\hline$g$ & $\begin{array}{l}\text { acceleration of gravity, } \\
\mathrm{m} / \mathrm{s}^{2}\end{array}$ & $\eta$ & efficiency, \% \\
\hline$h$ & $\begin{array}{l}\text { specific enthalpy, } \\
\mathrm{kJ} / \mathrm{kg}\end{array}$ & $\varphi$ & power factor, - \\
\hline$I$ & current, A & & \\
\hline$\dot{m}$ & mass flow, kg/h & \multicolumn{2}{|l|}{ Subscripts: } \\
\hline$p$ & pressure, MPa or bar & 0 & ambient state \\
\hline$P$ & power, kW & con & condensate \\
\hline$\dot{Q}$ & heat amount, kW & cum & cumulative \\
\hline & specific entropy, & en & energy \\
\hline$S$ & $\mathrm{~kJ} / \mathrm{kg} \cdot \mathrm{K}$ & ex & exergy \\
\hline$T$ & temperature, $\mathrm{K}$ or ${ }^{\circ} \mathrm{C}$ & IN & input (inlet) \\
\hline$U$ & voltage, $\mathrm{V}$ & $\mathrm{L}$ & loss \\
\hline$\dot{V}$ & $\begin{array}{l}\text { condensate volume } \\
\text { flow, } \mathrm{m}^{3} / \mathrm{h}\end{array}$ & OUT & output (outlet) \\
\hline$\dot{X}_{\text {heat }}$ & $\begin{array}{l}\text { heat exergy transfer, } \\
\text { kW }\end{array}$ & $\mathrm{p}$ & pump \\
\hline$Z$ & elevation, m & PPE & $\begin{array}{l}\text { Pump Producer } \\
\text { Efficiency }\end{array}$ \\
\hline
\end{tabular}

\section{References}

[1] Sakellaridis, N. F., Raptotasios, S. I., Antonopoulos, A. K., Mavropoulos, G. C., Hountalas, D. T.: Development and validation of a new turbocharger simulation methodology for marine two stroke diesel engine modelling and diagnostic applications, Energy 91, pp. 952-966, 2015. (doi: 10.1016/j. energy.2015.08.049)

[2] Raptotasios, S. I., Sakellaridis, N. F., Papagiannakis, R. G., Hountalas, D. T.: Application of a multi-zone combustion model to investigate the NOx reduction potential of twostroke marine diesel engines using EGR, Applied Energy 157, pp. 814-823, 2015. (doi: 10.1016/j.apenergy.2014.12.041)

[3] Mrzljak, V., Medica, V., Bukovac, O.: Volume agglomeration process in quasi-dimensional direct injection diesel engine numerical model, Energy 115, pp. 658-667, 2016. (doi: 10.1016/j.energy.2016.09.055)

[4] Sun, X., Liang, X., Shu, G., Lin, J., Wang, Y., Wang, Y.: Numerical investigation of two-stroke marine diesel engine emissions using exhaust gas recirculation at different injection time, Ocean Engineering 144, pp. 90-97, 2017. (doi: 10.1016/j. oceaneng.2017.08.044)

[5] Zhou, S., Gao, R., Feng, Y., Zhu, Y.: Evaluation of Miller cycle and fuel injection direction strategies for low NOx emission in marine two-stroke engine, International Journal of Hydrogen Energy 42 (31), pp. 20351-20360, 2017. (doi: 10.1016/j.ijhydene.2017.06.020) 
[6] Ryu, Y., Lee, Y., Nam, J.: Performance and emission characteristics of additives-enhanced heavy fuel oil in large two-stroke marine diesel engine, Fuel 182, pp. 850-856, 2016. (doi: 10.1016/j.fuel.2016.06.029)

[7] Raj, R., Ghandehariun, S., Kumar, A., Geng, J., Linwei, M.: A techno-economic study of shipping LNG to the Asia-Pacific from Western Canada by LNG carrier, Journal of Natural Gas Science and Engineering 34, pp. 979-992, 2016. (doi: 10.1016/j.jngse.2016.07.024)

[8] Fernández, I. A., Gómez, M. R., Gómez, J. R., Insua, A. A. B.: Review of propulsion systems on LNG carriers, Renewable and Sustainable Energy Reviews 67, pp. 1395-1411, 2017. (doi: 10.1016/j.rser.2016.09.095)

[9] Zhao, F., Yang, W., Tan, W. W., Yu, W., Yang, J., Chou, S. K.: Power management of vessel propulsion system for thrust efficiency and emissions mitigation, Applied Energy 161, pp. 124-132, 2016. (doi: 10.1016/j.apenergy.2015.10.022)

[10] Trivyza, N. L., Rentizelas, A., Theotokatos, G.: A novel multiobjective decision support method for ship energy systems synthesis to enhance sustainability, Energy Conversion and Management 168, pp. 128-149, 2018. (doi: 10.1016/j.enconman.2018.04.020)

[11] Gašpar, G., Poljak, I., Orović, J.: Computerized Planned Maintenance System Software Models, Scientific Journal of Maritime Research 32, pp. 141-145, 2018. (doi: 10.31217/p.32.1.14)

[12] Dorosz, P., Wojcieszak, P., Malecha, Z.: Exergetic Analysis, Optimization and Comparison of LNG Cold Exergy Recovery Systems for Transportation, Entropy 20(1), 59, 2018. (doi: 10.3390/e20010059)

[13] Bruk, E., Marinčić, E., Orović, J.: The optimization of the steam plant by means of an engine room simulator, Pomorstvo, vol. 24(1), 2010, pp. 41-52. (https://hrcak.srce.hr/54927)

[14] Orović, J., Mrzljak, V., Poljak, I.: Efficiency and Losses Analysis of Steam Air Heater from Marine Steam Propulsion Plant, Energies 2018, 11 (11), 3019; (doi: 10.3390/en11113019)

[15] Wang, C., Zhu, Y.: Entransy analysis on boiler air pre-heater with multi-stage LHS unit, Applied Thermal Engineering 130, pp. 1139-1146, 2018. (doi: 10.1016/j.applthermaleng.2017.11.085)

[16] Hajebzadeh, H., Ansari, A. N. M., Niazi, S.: Mathematical modeling and validation of a 320 MW tangentially fired boiler: A case study, Applied Thermal Engineering 146, pp. 232-242, 2019. (doi: 10.1016/j.applthermaleng.2018.09.102)

[17] Medica-Viola, V., Pavković, B., Mrzljak, V.: Numerical model for on-condition monitoring of condenser in coal-fired power plants, International Journal of Heat and Mass Transfer 117, pp. 912-923, 2018. (doi: 10.1016/j.ijheatmasstransfer.2017.10.047)

[18] Mrzljak, V., Poljak, I., Medica-Viola, V.: Energy and Exergy Efficiency Analysis of Sealing Steam Condenser in Propulsion System of LNG Carrier, International Journal of Maritime Science \& Technology "Our Sea” 64 (1), pp. 20-25, 2017. (doi: 10.17818/NM/2017/1.4)

[19] Mrzljak, V., Poljak, I., Medica-Viola, V.: Efficiency and losses analysis of low-pressure feed water heater in steam propulsion system during ship maneuvering period, Scientific Journal of Maritime Research 30, pp. 133-140, 2016. (https:// hrcak.srce.hr/171454)

[20] Burin, E. K., Vogel, T., Multhaupt, S., Thelen, A., Oeljeklaus, G., Gorner, K., Bazzo, E.: Thermodynamic and economic evaluation of a solar aided sugarcane bagasse cogeneration power plant, Energy 117, Part 2, pp. 416-428, 2016. (doi: 10.1016/j.energy.2016.06.071)

[21] Mrzljak, V., Poljak, I., Medica-Viola, V.: Thermodynamical analysis of high-pressure fed water heater in steam propulsion system during exploitation, Shipbuilding: Theory and Practice of Naval Architecture, Marine Engineering and Ocean Engineering 68 (2), pp. 45-61, 2017. (doi: 10.21278/ brod68204)

[22] Mrzljak, V., Poljak, I., Žarković, B.: Exergy Analysis of Steam Pressure Reduction Valve in Marine Propulsion Plant on Conventional LNG Carrier, International Journal of Maritime Science \& Technology "Our Sea" 65(1), pp. 24-31, 2018. (doi: 10.17818/NM/2018/1.4)

[23] Mrzljak, V., Poljak, I., Mrakovčić, T.: Energy and exergy analysis of the turbo-generators and steam turbine for the main feed water pump drive on $L N G$ carrier, Energy Conversion and Management 140, pp. 307-323, 2017. (doi: 10.1016/j. enconman.2017.03.007)

[24] Hafdhi, F., Khir, T., Ben Yahyia, A., Ben Brahim, A.: Energetic and exergetic analysis of a steam turbine power plant in an existing phosphoric acid factory, Energy Conversion and Management 106, pp. 1230-1241, 2015. (doi: 10.1016/j. enconman.2015.10.044)

[25] Mrzljak, V., Senčić, T., Žarković, B.: Turbogenerator Steam Turbine Variation in Developed Power: Analysis of Exergy Efficiency and Exergy Destruction Change, Modelling and Simulation in Engineering 2018. (doi: 10.1155/2018/2945325)

[26] Sihnko Ind. Ltd., EVZ Condensate pumps, https://www. shinkohir.co.jp/en/product.html (accessed: 20.09.18.)

[27] Final drawing for condensate centrifugal pump, Sihnko Ind. Ltd., Hiroshima, Japan, 2006. - internal ship documentation

[28] Kanoğlu, M., Çengel, Y.A., Dincer, I.: Efficiency Evaluation of Energy Systems, Springer Briefs in Energy, Springer, 2012. (doi: 10.1007/978-1-4614-2242-6)

[29] Mrzljak, V., Prpić-Oršić, J., Senčić, T.: Change in Steam Generators Main and Auxiliary Energy Flow Streams During the Load Increase of LNG Carrier Steam Propulsion System, Scientific Journal of Maritime Research 32, pp. 121-131, 2018. (doi: 10.31217/p.32.1.15)

[30] Tan, H., Shan, S., Nie, Y., Zhao, Q.: A new boil-off gas re-liquefaction system for LNG carriers based on dual mixed refrigerant cycle, Cryogenics 92, pp. 84-92, 2018. (doi: 10.1016/j. cryogenics.2018.04.009)

[31] Mrzljak, V.: Low power steam turbine energy efficiency and losses during the developed power variation, Technical Journal 12 (3), pp. 174-180, 2018. (doi: 10.31803/tg20180201002943)

[32] Moran M., Shapiro H., Boettner, D. D., Bailey, M. B.: Fundamentals of engineering thermodynamics, Seventh edition, John Wiley and Sons, Inc., 2011.

[33] Bühler, F., Van Nguyen, T., Kjær Jensen, J., Müller Holm, F., Elmegaard, B.: Energy, exergy and advanced exergy analysis of a milk processing factory, Energy 162, pp. 576-592, 2018. (doi: 10.1016/j.energy.2018.08.029)

[34] Ahmadi, G. R., Toghraie, D.: Energy and exergy analysis of Montazeri Steam Power Plant in Iran, Renewable and Sustainable Energy Reviews 56, pp. 454-463, 2016. (doi: 10.1016/j.rser.2015.11.074)

[35] Akbari, N.: Introducing and 3E (Energy, Exergy, Economic) analysis of an integrated tran-scritical $\mathrm{CO}_{2}$ Rankine cycle, Stirling power cycle and $L N G$ regasification process, Applied Thermal Engineering 140, pp. 442-454, 2018. (doi: 10.1016/j.applthermaleng.2018.05.073) 
[36] Taner, T., Sivrioglu, M.: Energy-exergy analysis and optimisation of a model sugar factory in Turkey, Energy 93, pp. 641654, 2015. (doi:10.1016/j.energy.2015.09.007)

[37] Kowalczyk, T., Ziółkowski, P., Badur, J.: Exergy Losses in the Szewalski Binary Vapor Cycle, Entropy 17, pp. 7242-7265, 2015. (doi: 10.3390/e17107242)

[38] Uysal, C., Kurt, H., Kwak, H. Y.: Exergetic and thermoeconomic analyses of a coal-fired power plant, International Journal of Thermal Sciences 117, pp. 106-120, 2017. (doi: 10.1016/j. ijthermalsci.2017.03.010)

[39] Erdem, H.H., Akkaya, A.V., Cetin, B., Dagdas, A., Sevilgen, S.H., Sahin, B., Teke, I., Gungor, C., Atas, S.: Comparative energetic and exergetic performance analyses for coal-fired thermal power plants in Turkey, International Journal of Thermal Sciences 48, pp. 2179-2186, 2009. (doi: 10.1016/j.ijthermalsci.2009.03.007)

[40] Dincer, I., Midilli, A., Kucuk, H.: Progress in Exergy, Energy and the Environment, Springer International Publishing, 2014. (doi: 10.1007/978-3-319-04681-5)

[41] Lemmon, E.W., Huber, M.L., McLinden, M.O.: NIST reference fluid thermodynamic and transport properties-REFPROP, version 9.0, User's guide, Colorado, 2010.

[42] Cengel Y., Boles M.: Thermodynamics an engineering approach, Eighth edition, McGraw-Hill Education, 2015.
[43] Szargut, J.: Exergy Method - Technical and Ecological Applications, WIT Press, 2005.

[44] https://www.greisinger.de (accessed: 21.09.18.)

[45] http://www.industriascontrolpro.com (accessed: 22.09.18.)

[46] https://portal.endress.com (accessed: 21.09.18.)

[47] Fluke 325 True RMS AC/DC Clamp Meter, https://www. jameco.com/Jameco/Products/ProdDS/2173263.pdf (accessed: 25.09.18.)

[48] Chen, W.K.: The electrical engineering handbook, Elsevier Academic Press, 2004.

[49] Maxfield, C., Bird, J., Laughton, M.A., Bolton, W., Leven, A., Schmitt, R., Sueker, K., Williams, T., Tooley, M., Moura, L., Darwazeh, I., Kester, W., Bensky, A., Warne, D.F.: Electrical Engineering, Elsevier Inc., 2008.

[50] Adibhatla, S., Kaushik, S. C.: Energy and exergy analysis of a super critical thermal power plant at various load conditions under constant and pure sliding pressure operation, Applied Thermal Engineering 73, pp. 49-63, 2014. (doi: 10.1016/j. applthermaleng.2014.07.030)

[51] Mrzljak, V., Poljak, I., Medica-Viola, V.: Dual fuel consumption and efficiency of marine steam generators for the propulsion of LNG carrier, Applied Thermal Engineering 119, pp. 331-346, 2017. (doi: 10.1016/j.applthermaleng.2017.03.078) 